\title{
La nueva actividad pública de fomento: el «green nudge» en la actual contratación pública
}

\author{
The new public activity of promotion: the "Green Nudge» \\ in the current public contracting
}

\author{
Daniel Terrón Santos \\ Universidad de Salamanca (España) \\ ORCID: http://orcid.org/0000-0001-9538-2248 \\ datersa@usal.es
}

\section{NOTA BIOGRÁFICA}

Doctor en Derecho por la Universidad de Salamanca, ocupa el puesto de Ayudante Doctor en la Facultad de Derecho. Docente en el Grado de Ciencias Políticas y Administración Pública y Director del Curso del INAP sobre «Nuevos Retos de la Contratación Pública», la contratación pública constituye una línea principal de investigación, integrada dentro de la actividad de la Administración Pública.

\section{RESUMEN}

Con la nueva Ley de Contratos del Sector Público se ha pasado a utilizar la contratación pública para lograr fines públicos distintos de los inicialmente previstos, hasta el punto de generar un probable encarecimiento del precio del contrato, en un uso desconocido, en principio, en los servidores públicos. No lo es tanto, la obligatoriedad de la inclusión de las cláusulas ambientales, imperativas en virtud de normativa específica. En su conjunto se presenta una actividad de fomento distinta de la tradicionalmente empleada por la Administración Pública. Cuestiones que es inevitable abordar, sin perder de vista la disyuntiva acerca del posible incumplimiento del principio de eficiencia que debe revestir la actividad contractual de toda Administración.

\section{PALABRAS CLAVE}

Contratos públicos; actividad de fomento; nudge; cláusulas ambientales; transversalidad; eficiencia.

\begin{abstract}
With the new Law of Contracts of the Public Sector it has passed to use the public contracting for achieving public ends different from the initially foreseen ones, up to the point of generating a probable increase of the price of the contract, in an unknown use, at first, in the public servants. It it is not so much, the obligatiry nature of the incorporation of the environmental, imperative clauses by virtue of specific regulation. In his set one presents an activity of promotion different from the traditionally used one for the Public Administration. Questions that it is inevitable to approach, without losing of sight the dilemma it brings over of the possible breach of the beginning of efficiency that must re-dress the contractual activity of any Administration.
\end{abstract}

\section{KEYWORDS}

Public contracts; public promotion activity; nudge; environmental clauses; transversality; efficiency. 


\begin{abstract}
SUMARIO
1. INTRODUCCIÓN. 2. CONTRATACIÓN PÚBLICA: «GREEN NUDGE» ¿LA NUEVA ACTIVIDAD DE FOMENTO? 3. LA TRANSVERSALIDAD AMBIENTAL EN LA LCSP, LA POSITIVACIÓN DEL NUDGE. 4. PERSPECTIVAAMBIENTAL EN EL OBJETO DEL CONTRATO. 5. LOS PLIEGOS: EL EJE DEL GREEN NUDGE. 6. SELECCIÓN DEL CONTRATISTA: UNA PERSPECTIVAAMBIENTAL. 7. REFERENCIA MEDIOAMBIENTAL EN LAADJUDICACIÓN Y EJECUCIÓN DEL CONTRATO. 8. CONCLUSIONES. 9. BIBLIOGRAFÍA.
\end{abstract}

\title{
1. INTRODUCCIÓN
}

La nueva Ley de Contratos del Sector Público, pese a su juventud, ya está ampliamente comentada por la doctrina por citar algunos (Gimeno Feliú, et al., 2018), (Palomar Olmeda y Garcés Sanagustín et al., 2018), luego no es objeto de este trabajo glosar la misma, ni en todo ni en parte, sino sólo analizar el texto legal desde la perspectiva del nudge. La Unión Europea, al aprobar las Directivas 2014/24/UE, 2014/25/UE, y 2014/23/UE, finalizó con la revisión y modernización de las normas sobre contratación pública, con los objetivos de incrementar la eficiencia del gasto, la participación de PYMES en la contratación pública, así como facilitar que los Poderes Públicos empleen la contratación en apoyo de objetivos sociales comunes, incluyendo una integración adecuada de requisitos medioambientales, más allá de aquellos que son impuestos por las normas vigentes sobe la materia.

En ese punto, diríamos que se persigue, que el control del cumplimiento de las disposiciones de Derecho ambiental, social y laboral deba realizarse tanto cuando se apliquen los principios generales relativos a la elección de participantes y la adjudicación de contratos, como en la ejecución de éstos o al aplicar los criterios de exclusión o las disposiciones relativas a ofertas anormalmente bajas ${ }^{1}$.

La Directiva 2014/24/UE destaca el carácter estratégico de la contratación pública como medio de consecución de políticas sociales y ambientales ${ }^{2}$, siguiendo el principio de horizontalidad o transversalidad de la protección del medio ambiente, de acuerdo con el art. 11 del Tratado de Funcionamiento de la Unión Europea -antiguo art. 6 TCE- ${ }^{3}$. A estas referencias ambientales, ya incluidas en las Directivas de 2004, se añaden otras nuevas como el control de las obligaciones aplicables en materia medioambiental en la ejecución de los contratos, o la incorporación del coste del ciclo de vida de un producto ${ }^{4}$, servicio u obra como criterio de adjudicación del contrato; criterios que han de estar relacionados con la prestación objeto del contrato, puesto que, en otro caso, podrían ser contrarios a la libre competencia y a la igualdad de trato.

Con la Ley 9/2017, de 8 de noviembre, de Contratos del Sector Público (LCSP en adelante) $)^{5}$, por la que se trasponen las directivas comunitarias sobre la materia, se interiorizan los objetivos de las Directivas, tal como expresa su Exposición de Motivos (Apdo. II), al afirmar con claridad que los mismos son lograr una mayor transparencia en la contratación pública y conseguir una mejor relación calidad-precio, y para lograr éste último, se añade, se establece la obligación de los órganos de contratación de velar por que el diseño de los criterios de adjudicación permita obtener obras, suministros y servicios de gran calidad, concretamente mediante la inclusión de aspectos cualitativos, medioambientales, sociales e innovadores vinculados al objeto del contrato.

\footnotetext{
1 Así se recoge en la propia Exposición de Motivos de la Directiva 2014/24/UE, en particular vid. apartados 37, 40,41 y 99.

2 Precisamente es aquí donde se aprecia de forma directa la presencia de lo que se ha dado en denominar nudge, procurando así que la «nueva Administración» utilice todas las herramientas que posee, entre las que se incluye la contratación pública, para perseguir genéricamente el «buen gobierno» -llamado gobernanza- y procurar alcanzar una serie de resultados y tendencias entre las que, por supuesto, se incluyen las cuestiones ambientales y sociales.

3 Expresamente se determina que las exigencias de la protección del medio ambiente deberán integrarse en la definición y en la realización de las políticas y acciones de la Unión, en particular con objeto de fomentar un desarrollo sostenible.

4 Este concepto sirve para positivar de forma rotunda otra de las novedosas exigencias comunitarias: la economía circular. Si con algo podemos poner en relación a esta figura, sin lugar a dudas es con la sostenibilidad, dado su principal objetivo, que no es otro que procurar que no se pierda el valor de los productos, materiales y recursos (agua, energía, etc.), de forma que éste, una vez que entra a formar parte del ciclo económico no salga del mismo, de modo que se reduce la generación de residuos a niveles aceptables. Esto es la génesis de una nueva economía, caracterizada por la pérdida del tradicional carácter lineal que ha revestido a esta. Así se apuesta decididamente por lo que se ha dado en denominar «cerrar el ciclo de vida» de productos, servicios, residuos, materiales, tan fundamentales algunos de ellos como puedan ser el agua y la energía, lo que además hace necesario amparar bajo el paraguas de una perspectiva medioambiental a esta nueva realidad económica. A modo de resumen, la economía circular podría definirse como el punto donde confluyen los aspectos ambientales con los económicos.

5 Debe tenerse en cuenta, en su caso, la incidencia puntual sobre el texto de la Ley de la Orden HFP/1298/2017, de 26 de diciembre, por la que se publican los límites de los distintos tipos de contratos a efectos de la contratación del sector público a partir del 1 de enero de 2018 (BOE del 29).
} 


\section{CONTRATACIÓN PÚBLICA: «GREEN NUDGE» ¿LA NUEVA ACTIVIDAD DE FOMENTO?}

Como es preciso todo sistema de contratación, algo que no desconoce el actual de la LCSP, se caracteriza necesariamente por tener que ser más eficiente, transparente e íntegro que el anterior, en aras de mejorar el cumplimiento de los objetivos públicos ${ }^{6}$. Luego lo que vamos a observar es en el fondo una transformación precisamente de estos objetivos públicos y de los medios para alcanzarlos, al menos de la forma de emplearlos, distinta de la tradicional.

Por otra parte, «nudge» es un término anglosajón cuya traducción libre equivale a «pequeño empujón», es decir, un «toque», un impulso que consigue, al menos lo intenta, producir efectos en el sentido deseado. Luego la nueva normativa de contratación, en un sentido cierto -medioambiental en el caso que nos ocupa-, no es más, tampoco menos, que una estrategia de intervención pública dirigida a orientar inercialmente las decisiones en la línea considerada correcta por el poder público y el establishment, sin recurrir a la coacción ni a los incentivos económicos ${ }^{7}$. No se trata si no de encauzar los comportamientos hacia el logro de determinados objetivos públicamente deseables, sin forzar la libertad ni la autonomía de las personas, ni de las instituciones (Almonacid Lamelas, 2013).

Dicho de otro modo, nos encontramos ante la ya conocida actividad de fomento de los poderes públicos, de antiguo definida como la acción de la Administración encaminada a proteger o promover aquellas actividades, establecimientos o riquezas debidas a los particulares y que satisfacen necesidades públicas o se estiman de utilidad general, sin usar de la coacción ni crear servicios públicos (Jordana De Pozas, 1949: 4154) o por (Garrido Falla, 1952: 266) aquella actividad administrativa que se dirige a satisfacer indirectamente ciertas necesidades consideradas de carácter público protegiendo o promoviendo, sin emplear coacción, las actividades de los particulares o de otros entes públicos que directamente las satisfacen, pero alejada de los sistemas y mecanismos tradicionales de la misma.

En este punto nada nuevo parece que suponga la teoría del nudge de lo que a mediados del siglo XX ya apuntaba la doctrina administrativista patria. Ahondando en la otra de Thaler, el punto diferenciador lo encontramos, parcialmente, todo hay que decirlo, en el específico componente económico. En tanto que desde la perspectiva administrativista, se contemplaba la posibilidad, no siempre positivada, de intervención pública directa mediante aportaciones económicas tales como ayudas, becas, subvenciones, etc., algo que descarta el nudge, donde el poder público coadyuva pero siempre de forma indirecta, procurando que sea el sujeto privado el que cambie su comportamiento, ciertamente por tener en ciernes un resultado positivo, una recompensa, como pueda ser la adjudicación de un contrato, como consecuencia de un mayor grado de cumplimiento de medidas medioambientales, no obligatorias, o de otros comportamientos facultativos en ese mismo ámbito.

Esto lleva a plantearnos si la teoría del nudge no equivale a la búsqueda de un término medio entre la inhibición y el intervencionismo público, o lo que es lo mismo, acomodar la libertad de licitador al interés público a través de una influencia indirecta sobre su voluntad, para que quiera lo que conviene para la satisfacción de la necesidad pública de que se trate ${ }^{8}$.

Llámese fomento, en su concepción carente de intervención pública directa, o nominado como nudge, lo cierto es que la gobernanza va a encontrarse fuertemente influenciada por estos enfoques de influencia pública indirecta, que, sin duda alguna, van a innovarla. Empleando términos manidos, se persigue el siempre deseable «buen gobierno», como también se hace con otro tipo de actuaciones más concretas como pueda ser la implantación de la administración electrónica ${ }^{9}$.

\footnotetext{
6 Vid. Exposición de Motivos -Preámbulo- Apartado II.
}

7 Como es bien sabido, la teoría nudge saltó a la fama mundial en 2008 con el lanzamiento del libro Nudge: Improving decisions about Healt, Wealth and Happiness, de RICHARD THALER y CASS SUNSTEIN, en su edición en papel de 2017, Taurus, editado con el título Un pequeño empujón (nudge): el impulso que necesitas para tomar las mejores decisiones en salud, dinero y felicidad. Tal ha sido el impacto. Pero lo más importante, sin duda alguna, ha sido el seguimiento y aplicabilidad de la teoría, desde un primer momento, inicialmente en Estados Unidos y Reino Unido, sobre todo dentro del sector privado y luego adaptado a la sanidad pública y campos afines, pero se ha terminado por imponer, cierto es que mayoritariamente en el ámbito político, para procurar la consecución de objetivos de política interna. Este concepto, teoría, se basa en que el refuerzo positivo y las sugerencias indirectas son medios eficaces para terminar logrando, sin acudir a la imposición del cumplimiento forzoso, influir en las motivaciones, incentivos y toma de decisiones de grupos e individuos por igual. Se abandona la idea de que la forma más eficaz de lograr un comportamiento es la orden directa, la legislación, o la propia ejecución de la decisión previamente adoptada sin influencia externa alguna.

8 DE LA CUETARA MARTINEZ, J. M.: "Revisión de la noción española del fomento", en Revista Internacional de Ciencias Administrativas, vol. XLV-1979, núm. 1, págs. 29-35.

${ }^{9}$ La administración electrónica o «eGovernment» se define como la utilización de las tecnologías de la información y la comunicación (TIC) en las administraciones públicas, asociada a cambios en la organización y nuevas aptitudes del personal. El objetivo es 
Tradicionalmente se ha mostrado sumamente eficaz el empleo de técnicas pensadas para favorecer la superación de las tentaciones negativas que se presentan a los seres humanos en nuestros procesos de toma de decisiones. Nos vemos en la obligación de hacer nuestra la reflexión conforme la cual tendencias a las aproximaciones cortoplacistas, a la falta de establecimiento de prioridades, al despilfarro, etc., pueden ser atajadas más eficazmente si se utilizan mecanismos de autocontrol, apoyados en la filosofía del "empujoncito». La tendencia a reproducir comportamientos ajenos puede ser una ayuda, si enfatizamos los correctos. La gestión de la información en las organizaciones que componen el ámbito local puede ser determinante a la hora de implementar esos mecanismos de autocontrol. Junto a las rigurosas prohibiciones (pocas y muy cargadas de razón) hay que establecer mecanismos que garanticen que las buenas prácticas son puestas en el escaparate y las malas censuradas. La reflexión vale tanto para políticos como para funcionarios (Almonacid Lamelas, 2013). Defectos que no se solucionan normativamente. Sirva de ejemplo el texto del Estatuto Básico del Empleado Público, que nunca se ha terminado por cumplir en su totalidad, aun reconociendo su buen hacer teórico, o la Ley $3 / 2015$, de 30 de marzo, reguladora del ejercicio de alto cargo, por no decir la propia Ley 19/2013, de 9 de diciembre de Transparencia. Debemos dejar paso a los códigos éticos y, sobre todo a herramientas como la evaluación del desempeño, en lo que supone una aplicación directa del propio nudge, que precisamente permite ese salto del papel a la realidad.

Ya se manifestó acertadamente y se recordó (Rivero Ortega y Merino Estrada, 2013 a: 10 y ss., b: 10 y ss.) que una de las prácticas más rechazables generada en la etapa de "bonanza» y que actualmente irrita y deslegitima, es la de los gastos municipales «irracionales»: edificios faraónicos y gastos suntuarios. Aeropuertos innecesarios o paradas de AVE en los terrenos del sobrino. No es cuestión de establecer rigurosas normas reguladoras, o ahondar en la potestad de control o policía de la Administración, al fin y al cabo, sería redundar en lo mismo. En definitiva, la norma, per se, no cambia conductas, como tampoco la licitación electrónica conseguirá acabar con la contratación pública fraudulenta, aun cuando se cumpla escrupulosamente el nuevo procedimiento automático y transparente diseñado con tal fin ${ }^{10}$.

Dado que las normas ni pueden, ni deben desaparecer, no cabe ningún reproche si afirmamos que el nudge se convierte en el complemento ideal de las mismas. Bien entendido, previene gastos injustificados, procura una contratación y un manejo de las partidas de gastos en base a prácticas deseables y trasparentes, sin olvidar que dada la economía de escala en la que se nueve la Administración, casi siempre debería pagar menos que lo que pagaría un particular por el mismo producto.

Dicho esto, es difícil no entender que el nudge comprende un componente económico, lo que hace que se confunda, al menos hay riesgo de que así sea, con la tradicional actividad de fomento. Pagar más por el «mismo producto», puede verse sin duda alguna como un mecanismo de ayuda económica, aunque pueda considerarse indirecta dada la contraprestación de bienes y servicios existente.

No obstante, el componente económico del nudge hay que verlo y entenderlo desde la perspectiva de la eficacia y la eficiencia, ya que cuando hablamos de Administración y gasto público, no puede ser de otra manera. Como planteábamos al principio de este texto, pudiera parecer complicado defender que la Administración pague más por lo mismo. Prima facie, nos encontraríamos con la oposición frontal, no sólo de la opinión pública, si no muy probablemente de los órganos interventores del gasto público. Pero ambos conceptos, eficacia y eficiencia, también han sufrido considerables mutaciones en los últimos tiempos, no tanto en su conceptualización como en la aplicación efectiva de éstos a la realidad económica y social actual.

No debemos perder de vista que el medioambiente se ha terminado por convertir en un parámetro transversal de eficiencia, que cada área social debe cumplir para lograr satisfacer sus objetivos, por lo que debe concebirse de tal forma sus principios de protección y recomposición como el camino adecuado para poder hacer de las metas un hecho satisfactorio (Lucero Pantoja, 2018). Tradicionalmente, el derecho y la economía han sido las áreas más conscientes de esta realidad, transformándose continuamente para lograr satisfacer la armonía social en un sistema de intercambio mundial y condiciones de escases de recursos.

Aunque no siempre fue así, hoy todas las construcciones del modelo económico y jurídico evitan entrar en contradicción frente a los planteamientos ambientales, para así profundizar en el objetivo concreto que

mejorar los servicios públicos, reforzar los procesos democráticos y apoyar a las políticas públicas. Vid. Comunicación de la Comisión, de 26 septiembre 2003, al Consejo, al Parlamento Europeo, al Comité Económico y Social Europeo y al Comité de las Regiones. El papel de la administración electrónica en el futuro de Europa [COM (2003) 567 final].

10 Sólo queremos apuntar aquí de forma muy somera, que el algoritmo cuando menos corre el riesgo de ser el nuevo «ente» corrupto, o al menos debería considerársele susceptible de serlo, debiendo merecer todos los desvelos regulatorios o de cualquier otro tipo que se puedan mostrar eficaces para evitar o corregir tal circunstancia. 
se persigue tras las estructuras en formación del derecho ambiental. Tanto es así que la sensibilidad hacia el medio ambiente impregna, prácticamente, sino toda Ley, aunque quizás la herramienta más destacable para su protección, claramente dirigida hacia la sostenibilidad, sea la inclusión de criterios ambientales en aquellos ámbitos donde imperan otros principios.

Esta transformación no es precisamente nueva. Los primeros sesgos de cambio los encontrábamos en la legislación sobre contratación aparecida tras la C. E., máxime tras la incorporación de España a la Unión Europea ${ }^{11}$. La ímproba labor de la Comisión Interministerial para la Incorporación de Criterios Ambientales en la Contratación Pública, terminaría dando sus frutos ${ }^{12}$, sobre todo a raíz de la Ley 30/2007, de 30 de octubre, de Contratos del Sector Público ${ }^{13}$.

El siguiente salto cuantitativo, pero sobre todo cualitativo, lo da el Texto Refundido de la Ley de Contratos del Sector Público, aprobado por Real Decreto Legislativo 3/2011, de 14 de noviembre. Este texto, según contiene su propio art. 1, entre otros fines, perseguía, asegurar una eficiente utilización de los fondos destinados a la realización de obras, la adquisición de bienes y la contratación de servicios mediante la exigencia de la definición previa de las necesidades a satisfacer, la salvaguarda de la libre competencia y la selección de la oferta económicamente más ventajosa ${ }^{14}$.

Por tanto, pagar más por lo mismo, no puede considerarse como una ayuda encubierta o indirecta, en el mejor de los casos, sino que se trata de una mera consecuencia del nudge, en tanto que lo que ocurre es que el cumplimiento de los fines que la Administración persigue por parte de los particulares va a encarecer el coste de un producto, sobrecoste que se va a trasladar al precio del mismo. Nada nuevo aportamos al decir que los productos ambientalmente sostenibles son más caros de producir que aquellos que no lo son. Pero a la vez, dado que los particulares adecúan su comportamiento a lo que la Administración previamente ha determinado como objetivos deseables, implica que ésta tenga que destinar menos recursos públicos

11 Una primera pincelada la encontramos en la Ley 11/1997, de 24 de abril, de Envases y Residuos de Envases, que estableció para las Administraciones públicas la obligación de promover el uso de materiales reutilizables y reciclables en la contratación de obras públicas y suministros (Disposición Adicional 13. ${ }^{a}$ ). Cuestión a la que, en el ámbito del Ministerio de Medio Ambiente, dio cumplimiento la Orden Ministerial de 14 de octubre de 1997, por la que se fijaban los criterios de modificación de los Pliegos de Cláusulas Administrativas Particulares que habían de regir la contratación en el Ministerio de Medio Ambiente para incluir la valoración ambiental como exigencia objetiva de resolución de los concursos que se convoquen (derogada por Orden MAM/2116/2007, de 10 de julio, sobre requisitos y criterios medioambientales a introducir en los pliegos de cláusulas administrativas que rijan en los contratos del Ministerio de Medio Ambiente y los Organismos Públicos de él dependientes). Por su parte, la Ley 10/1998, de 21 de abril, de Residuos, vino a obligar a las Administraciones Publicas a promover el uso de materiales reutilizables, reciclables y valorizables, así como de productos fabricados con material reciclado que cumplan las especificaciones técnicas requeridas, en el marco de la contratación pública de obras y servicios (art. 26.2), y la Ley 37/2003, de 17 de noviembre, del Ruido, determinó que las Administraciones Públicas promoverán el uso de maquinaria, equipos y pavimentos de baja emisión acústica, especialmente al contratar las obras y suministros (Exposición de Motivos -IV-).

12 Tras su creación por Acuerdo de 22 de mayo de 2006, fue la sede en la que se gestó el Plan de Contratación Pública Verde de la Administración General del Estado y sus Organismos Públicos y las Entidades Gestoras de la Seguridad Social, aprobado por Acuerdo del Consejo de Ministros de 11 de enero de 2008, y publicado en la Orden PRE/116/2008, de 21 de enero.

13 Este nuevo texto legal tuvo por finalidad incorporar a nuestro ordenamiento la Directiva 2004/18/CE, incluyendo con normalidad los criterios ambientales en los procesos de contratación. Con carácter previo, ya en la STJUE de 17 de septiembre de 2002 , conocida como Sentencia Concordia, comentada acertadamente por MARTíNEZ PALLARES, 2004: págs. 161-171, se analizaba la validez de incluir entre los criterios de adjudicación del contrato la organización del empresario en materia de calidad y de medio ambiente (debían concederse puntos adicionales por un conjunto de criterios cualitativos y por un programa de conservación del medio ambiente acreditados mediante certificación) y la reducción de las emisiones de óxido de nitrógeno o del nivel de ruido de los vehículos (criterios de naturaleza ecológica) se afirma que:

«(...), en el marco de un contrato público relativo a la prestación de servicios de transporte urbano en autobús, la entidad adjudicadora decide adjudicar un contrato al licitador que ha presentado la oferta económicamente más ventajosa, puede tener en cuenta criterios ecológicos, como el nivel de las emisiones de óxidos de nitrógeno o el nivel de ruido de los autobuses, siempre que tales criterios estén relacionados con el objeto del contrato, no confieran a dicha entidad adjudicadora una libertad incondicional de elección, se mencionen expresamente en el pliego de condiciones o en el anuncio de licitación y respeten todos los principios fundamentales del Derecho comunitario y, en particular, el principio de no discriminación. 2) El principio de igualdad de trato no se opone a que se tomen en consideración criterios relacionados con la protección del medio ambiente, como los controvertidos en el asunto principal, por el mero hecho de que la propia empresa de transportes de la entidad adjudicadora sea una de las pocas empresas que pueden ofrecer unos vehículos que cumplan los criterios mencionados».

14 Todo ello directamente relacionado con la calidad del medio ambiente y, sobre todo, con el uso de los denominados recursos naturales. En definitiva, se procura dar una definición al producto, obra o servicio que el adjudicador quiere/necesita adquirir desde una perspectiva ambiental. Definición que estará caracterizada por la ausencia de influencias, siendo su único límite el respeto a los principios y normas, tanto comunitarias como nacionales, sobre la materia. En todo caso habrá que respetar la normativa sobre libre competencia y transparencia en los procedimientos de contratación; pero haciéndolo desde una perspectiva ambiental, de tal forma que quede vinculado el objeto del contrato con los criterios ambientales, utilizando conceptos y justificaciones relacionadas con el desarrollo sostenible y el medio ambiente. También sienta las bases de las prohibiciones de contratar relacionadas con el medioambiente, siendo pionera en incorporar cuestiones ambientales en relación con la capacidad y solvencia de los empresarios. 
directos al mismo fin. Por ello, habrá que elaborar un análisis que comprenda el sobrecoste de la nueva contratación y lo ponga en relación con el previsible ahorro inversor de la Administración en aquellos campos donde el nudge ha conseguido que los sujetos se adecuen "voluntariamente» a estándares o parámetros públicamente deseables. Sólo de esta manera podremos hablar realmente de eficiencia en el nudge.

Obviamente hay un riesgo que a simple vista a nadie se le debe escapar. Los números son empíricos y, cuando el sobrecoste sea mayor que el ahorro de inversión, cuestión aparte es lo complicado de determinar estos extremos y por tanto poder llevar a cabo la operación, será más que cuestionable poder hablar de eficiencia, debiendo basar el comportamiento público en otros principios.

\section{LA TRANSVERSALIDAD AMBIENTAL EN LA LCSP, LA POSITIVACIÓN DEL NUDGE}

Con todo, es mucho más profusa la redacción de la LCSP sobre la materia, al incluir a lo largo de todo su articulado referencias directas a este concepto, cierto es que sin nombrarlo, pero respondiendo perfectamente al tipo que hemos detallado. No hay más que detenerse en el propio art. 1, relativo al objeto y finalidad de la misma, que proclama rotundamente, conforme al Derecho europeo y la trascendencia actual de la cuestión -empujón mediante-, la incorporación legal de los aspectos medioambientales (y también de los sociales, aunque estos no son objeto de este trabajo), al precisar que, en toda contratación pública se incorporarán de manera transversal y preceptiva criterios medioambientales siempre que guarden relación con el objeto del contrato, en la convicción de que su inclusión proporciona una mejor relación calidad-precio en la prestación contractual, así como una mayor y mejor eficiencia en la utilización de los fondos públicos.

Precisamente el recurso a la transversalidad, uno de los conceptos más mencionados, pero menos comprendidos y abordados en los procesos de gestión social y ambiental ${ }^{15}$, es lo que caracteriza el nuevo texto de contratación pública. A nuestro juicio, nudge y transversalidad son dos conceptos que indefectiblemente han de ir de la mano. De poco sirve al legislador utilizar la contratación pública para logar ciertos fines mediatos de carácter ambiental, si ello no supone afectarla transversalmente en todos, o en la mayor parte, de sus aspectos, desde idéntica perspectiva.

No obstante, este es un tema que, por necesario que resulte, no va a carecer de complejidad. Dada la necesaria relación entre los criterios ambientales y el propio objeto del contrato, no podemos entender ésta sino es partiendo del hecho cierto de que ambos criterios (principalmente en cuanto se refiere a la adjudicación de los contratos), no pueden ir en contra o suponer un obstáculo a los principios esenciales de la contratación pública-igualdad y no discriminación. Es el propio art. 1 LCSP el que se encarga de establecer esta premisa ${ }^{16}$. La finalidad del principio de igualdad es favorecer el desarrollo de una competencia real y efectiva, por lo que impone que todos los licitadores dispongan de las mismas oportunidades al formular sus ofertas y que estas se sometan a las mismas condiciones para todos los licitadores ${ }^{17}$; de ahí la necesidad de utilizar la incorporación de criterios ambientales en el objeto del contrato de forma positiva, nunca como obstáculos para la igualdad y la libre competencia ${ }^{18}$.

De hecho, las Entidades del sector público valorarán, entre otras, la incorporación de consideraciones medioambientales y de innovación como aspectos positivos en los procedimientos de contratación pública,

15 Contemplar el medio ambiente desde una perspectiva transversal implica que sus valores, principios y normas, contenidos tanto en instrumentos internacionales como, sobre todo, en la legislación interna de los Estados, nutren e impregnan por entero al ordenamiento jurídico.

16 Literalmente el art. 1.3 dispone que en toda contratación pública se incorporarán de manera transversal y preceptiva criterios sociales y medioambientales siempre que guarde relación con el objeto del contrato, en la convicción de que su inclusión proporciona una mejor relación calidad-precio en la prestación contractual, así como una mayor y mejor eficiencia en la utilización de los fondos públicos. Tampoco podemos olvidarnos del art. 132 LCSP, en la parte dedicada a la adjudicación de los contratos (teniendo en cuenta que en la Directiva 2014/24/UE se establecen en su art. 18 los principios aplicables a toda la contratación, como afirma la STJUE de 16 de septiembre de 2013, T-2/07, España/Comisión).

17 Así pueden verse las Sentencias del TJUE de 12 de marzo de 2015, C-538/13, y de 14 de diciembre de 2016, C-171/15, entre otras muchas.

18 Tanto es así, que el propio texto del art. 18 de la Directiva 2014/24/UE, estipula que los Estados miembros tomarán las medidas pertinentes para garantizar que, en la ejecución de contratos públicos, los operadores económicos cumplen las obligaciones aplicables en materia medioambiental, social o laboral establecidas en el Derecho de la Unión, el Derecho nacional, los convenios colectivos o por las disposiciones de Derecho internacional medioambiental, social y laboral enumeradas en el anexo X. Es decir, el medioambiente no sólo sirve claramente como criterio de selección, entendiendo que quienes no cumplen las obligaciones ambientales vulneran pues las propias condiciones de igualdad entre licitadores, sino que afecta igualmente a la transparencia, en tanto que la contratación, en sus documentos (pliegos), tiene que contemplar expresamente el cumplimiento de la obligación ambiental para todos los licitadores. 
en los términos previstos en la propia Ley -vid. art. 28.2-. Ya se puso de manifiesto que es posible una contratación pública sostenible que combine adecuadamente criterios económicos con criterios sociales y ambientales, (Vara Arribas, 2008: 128), siendo reafirmada la idea posteriormente (Pernas García, 2012: 299323). Así se convierte el medio ambiente en un criterio estratégico para la contratación pública. Luego son tres los conceptos relacionados y presentes en la contratación pública: "green nudge», «transversalidad» y «uso estratégico».

También incide de manera importante en la capacidad del ofertante, al incluirse la cuestión ambiental en el contenido de los requisitos que ha de cumplir para poder ser contratista ${ }^{19}$. En relación con la capacidad para contratar, la LCSP establece una serie de prohibiciones de contratar que impiden hacerlo a las personas en quienes concurran determinadas circunstancias, entre las que se incluyen: haber sido condenadas mediante sentencia firme por delitos relativos a la ordenación del territorio y el urbanismo, la protección del patrimonio histórico y el medio ambiente (prohibición que alcanza a las personas jurídicas que sean declaradas penalmente responsables, y a aquellas cuyos administradores o representantes, de hecho o de derecho, vigente su cargo o representación y hasta su cese, se encontraran en la situación mencionada), y haber sido sancionadas con carácter firme por infracción muy grave en materia medioambiental de conformidad con lo establecido en la normativa vigente ${ }^{20}$.

Igualmente impide contratar, haber incumplido las cláusulas que son esenciales en el contrato, incluyendo las condiciones especiales de ejecución establecidas de acuerdo con lo señalado en el art. 202, cuando dicho incumplimiento hubiese sido definido en los pliegos o en el contrato como infracción grave, concurriendo dolo, culpa o negligencia en el empresario, y siempre que haya dado lugar a la imposición de penalidades o a la indemnización de daños y perjuicios ${ }^{21}$. Este precepto establece que los órganos de contratación puedan determinar condiciones especiales en relación con la ejecución del contrato, siempre que estén vinculadas al objeto del contrato, no sean directa o indirectamente discriminatorias, sean compatibles con el derecho comunitario y se indiquen en el anuncio de licitación y en los pliegos ${ }^{22}$.

En cuanto a los efectos de las anteriores, el art. 72 señala que la prohibición de contratar por las causas previstas en el art. 71.1, a y b, se apreciará directamente por los órganos de contratación, cuando la sentencia o la resolución administrativa se hubiera pronunciado expresamente sobre su alcance y duración, subsistiendo durante el plazo señalado en las mismas; en el caso de que la sentencia o la resolución administrativa no contengan pronunciamiento sobre el alcance o duración de la prohibición de contratar y en los supuestos del art. 71.2 el alcance y duración de la prohibición deberá determinarse mediante un procedimiento administrativo instruido al efecto (regulado en el mismo precepto). En los casos en que por sentencia penal firme así se prevea, la duración de la prohibición de contratar será la prevista en la misma, si no se ha establecido plazo, esa duración no podrá exceder de cinco años desde la fecha de la condena por sentencia firme; en el resto de los supuestos, el plazo de duración no podrá exceder de tres años ${ }^{23}$.

Sobre las prohibiciones de contratar y sus efectos, hay de distinguir entre aquellas cuya declaración corresponda al Ministro de Hacienda y Función Pública ${ }^{24}$, que producirá efectos en todo el sector público (desde la fecha en que devinieron firmes la sentencia o la resolución), y las del art. 71.2 (cuyos efectos se producen desde la fecha de inscripción en el registro correspondiente), en las que la prohibición de contratar afectará al ámbito del órgano de contratación competente para su declaración (aunque pueden extenderse a todo el sector público correspondiente, según los casos). Prohibiciones de contratar que se comunicarán sin dilación para su inscripción al Registro Oficial de Licitadores y Empresas Clasificadas del Sector Público o el equivalente en el ámbito de las Comunidades Autónomas; y su inscripción caducará a los 3 meses desde que termine su duración, debiendo procederse de oficio a su cancelación en dicho Registro.

19 En todo caso se deben cumplir los requisitos que se explicitan -art. 65 LCSP-, entre los que se incluyen que tengan plena capacidad de obrar, no estén incursas en alguna prohibición de contratar, y acrediten su solvencia económica y financiera y técnica o profesional (o, en los casos en que así lo exija la Ley, se encuentren debidamente clasificadas).

20 Art. 71.1, letras a) y b).

21 Art. 71.2.c).

22 Será obligatorio establecer en el Pliego de Cláusulas Administrativas Particulares al menos una de las condiciones especiales de ejecución de entre, en especial, las relativas a consideraciones relacionadas con la innovación o de tipo medioambiental, entre otras. Las prohibiciones de contratar afectan también a aquellas empresas de las que, por razón de las personas que las rigen o de otras circunstancias, pueda presumirse que son continuación o que derivan, por transformación, fusión o sucesión, de otras empresas en las que hubiesen concurrido aquellas.

${ }^{23}$ En todo caso, habrá que estar a lo dispuesto en el propio art. 72 en cuanto se refiere a plazos -art. 72.6-, competencia para declarar la prohibición -art. 72.4- y excepciones -art. 72.5-.

24 Vid. art. 73 LCSP. 
Corresponderá la carga de la prueba de no estar incurso en prohibición de contratar al empresario, pudiendo realizarse mediante testimonio judicial o certificación administrativa, según los casos (art. 85 LCSP). De hecho, entre la documentación que los empresarios interesados en la licitación han de acreditar -mediante declaración responsable- se incluye la de no estar incurso en ninguna prohibición de contratar (art. 140 LCSP).

Por otra parte, para poder contratar se exige a los empresarios acreditar solvencia técnica o profesional, o, si así se prevé, estar clasificados ${ }^{25}$. Los medios para acreditar la solvencia del empresario varían en función del contrato concreto, haciendo referencia al medio ambiente algunos de los previstos. Así, en los contratos de obras y de servicios, se incluye la indicación de las medidas de gestión medioambiental que el empresario podrá aplicar al ejecutar el contrato (arts. 881.d) y 90.1.f); en el supuesto de contratos de suministro se admiten los certificados expedidos por los institutos o servicios oficiales encargados del control de calidad, de competencia reconocida (art. 89.1.f), en los restantes contratos, se aplica la referencia a las medidas de gestión medioambiental que se podrán aplicar al ejecutar el contrato (art. 91). Los contratos de regulación armonizada (art. 19), exigirán certificados de organismos acreditados para certificar el cumplimiento de las normas de gestión medioambiental, necesariamente referidos al Sistema Comunitario de Gestión y Auditoría Medioambientales (EMAS) de la Unión Europea ${ }^{26}$, o a otros sistemas de gestión medioambiental reconocidos por esta u otras normas de gestión medioambiental basadas en normativa europea o internacional (art. 94 LCSP) 27.

Quizá los términos nudge y uso estratégico son los más coincidentes, sin perjuicio de que este último puede atender también a otras definiciones, aunque aplicado a la materia ambiental en la contratación supone emplear los contratos públicos para procurar objetivos ambientalmente deseables, lo que lo convierte en una auténtica actividad de fomento o nudge. Transversalidad, sin embargo es un concepto, obviamente con relación directa, pero sentido distinto. Más bien, hace referencia a que no se puede limitar la cuestión ambiental al mero objeto del contrato o al cumplimiento de ciertos requisitos por los licitadores, sino que, muy al contrario, ésta debe estar presente a lo largo de todo el proceso y todos los trámites de la contratación.

\section{PERSPECtIVA AMBIENTAL EN EL OBJETO DEL CONTRATO}

Transversalidad mediante, no podemos dejar de referir que una de las novedades más destacables de la LCSP en relación con la integración de las consideraciones ambientales en su texto, son los cambios producidos en la regulación del objeto del contrato (cuya importancia para impedir que los criterios ambientales se consideren contrarios al principio de igualdad ya hemos subrayado). Como negar que el objeto de los contratos públicos es uno de sus elementos esenciales. Precisamente es el objeto, por referirse a aquello que ha de realizar el contratista (obras, suministros, prestación de servicios, etc.), lo que permite distinguirlos y establecer su régimen jurídico.

Como consecuencia, la LCSP (art. 99.1) establece que el objeto de los contratos del sector público, igual que en los privados, será determinado, pues las partes han de saber a qué se obligan. Por analogía, el Código Civil (arts. 1261 y 1271 a 1273) obliga a que el objeto de los contratos sea cierto, posible, lícito y determinado; exigencias que, por derivar del Ordenamiento en su conjunto, pueden aplicarse a los contratos públicos, pese a no mencionarse expresamente en la LCSP.

Pero la novedad más destacable introducida por la LCSP en cuanto al objeto del contrato es que se podrá definir en atención a las necesidades o funcionalidades concretas que se pretenden satisfacer, sin cerrarlo a una solución única. Especialmente, se definirán de este modo en aquellos contratos en los que se estime que pueden incorporarse innovaciones tecnológicas o ambientales que mejoren la eficiencia y

25 Ex art. 65 LCSP.

26 El Registro EMAS es una herramienta de carácter voluntario, diseñada por la Comisión Europea para la inscripción y reconocimiento público de aquellas empresas y organizaciones que tienen implantado un sistema de gestión ambiental que les permite evaluar, gestionar y mejorar sus impactos ambientales, asegurando así un comportamiento excelente en este ámbito. Este reconocimiento, ya sean compañías industriales, PYMES, organizaciones del sector servicios, administraciones públicas, etc., acredita que tienen una política ambiental definida, hacen uso de un sistema de gestión medioambiental y dan cuenta periódicamente del funcionamiento de dicho sistema a través de una declaración medioambiental verificada por organismos independientes. Con el logotipo EMAS, se garantiza la fiabilidad de la información dada por dicha empresa.

27 En estos supuestos, la acreditación de la gestión ambiental reconocida se acredita mediante el correspondiente certificado, no siendo necesario realizar ningún otro trámite adicional. Resumiendo, la obtención o distinción con un determinado logotipo terminará por servir de acreditación al respecto. 
sostenibilidad de los bienes, obras o servicios que se contraten. Precisamente es aquí donde se positiviza de forma expresa el green nudge en la contratación pública.

Al margen de las prohibiciones o restricciones en la contratación vinculadas a cumplimiento de condiciones ambientales o a la ausencia de incumplimientos, la posibilidad por la que el Sector Público pueda actuar a favor de actuaciones sostenibles, de una manera transversal u horizontal, pero de forma directa, qué duda cabe, confiere carácter estratégico (green nudge) a la contratación pública, de acuerdo con las directrices de la Unión Europea.

Debe acentuar la consideración de los criterios de adjudicación de los contratos como verdadera extensión de la definición del objeto de éstos, de ahí que volvamos a encontrarnos con la trascendencia de las consideraciones ambientales como uno de tales criterios, y su estrecha relación con la igualdad de trato y la transparencia. Se logra con ello positivizar el manido concepto de economía circular al comprenderlo como una manifestación del green nudge. Al fin y al cabo, su objetivo no es otro que implementar una nueva economía, circular -no lineal-, basada en el principio de «cerrar el ciclo de vida» de los productos, los servicios, los residuos, los materiales, el agua y la energía, todo ello bajo el paraguas de una clara perspectiva medioambiental ${ }^{28}$.

Viene dado que la contratación pública necesita de un procedimiento determinado, que por la propia naturaleza de la materia, necesariamente va a ser de cierta complejidad ${ }^{29}$. No hay que olvidar que es preciso procurar la mejor solución para el interés general, apreciando el mismo desde la perspectiva más amplia posible, lo que exige tener en cuenta consideraciones ambientales. Así, entre aquellas actuaciones que resultan preciso para la preparación de los contratos al objeto de lograr la su adjudicación, se encuentren los pliegos de cláusulas. Tanto los PCAP como los PPT, son los documentos en los que se contienen las condiciones jurídicas, económicas y técnicas a las que ha de ajustarse la licitación, adjudicación y ejecución de los contratos públicos; es decir, fijan el contenido de los contratos afectando al objeto del contrato, en tanto que lo detallan, perfilan e incluso, condiciones ambientales mediante, pueden determinan como se ha de procurar por los licitadores.

\section{LOS PLIEGOS: EL EJE DEL GREEN NUDGE}

No cabe duda de que el principio de legalidad impera en la contratación pública, lo que no es óbice para que las Administraciones se beneficien del principio de libertad de pactos (art. 34 LCSP). Así visto, respetando el límite que supone el primero de los principios enunciados, los poderes públicos tienen cierta libertad para incluir en los contratos algunas condiciones ${ }^{30}$. El imperio de lo público se plasma precisamente en estos documentos, pliegos de cláusulas, con la finalidad de poner a salvo a las Administraciones y demás entes de sorpresas e incertidumbres que podrían derivar de la asunción de la libertad del ámbito privado. La discrecionalidad sólo va a suponer poder elegir entre las herramientas legales a emplear para alcanzar el objetivo de satisfacer el interés público, nunca para ponderar otros fines ajenos al mismo.

La LCSP, como ya es tradicional, distingue entre los Pliegos de Cláusulas Administrativas Generales y Particulares, que de carácter jurídico, administrativo y económico, determinan los derechos y obligaciones del contrato ${ }^{31}$.

28 En este sentido, el art. 145.1 LCSP, vincula la adjudicación de los contratos con el empleo de una pluralidad de criterios de adjudicación en base a la mejor relación calidad-precio. Entre ellos, siempre que se encuentre justificado en el expediente, los contratos se podrán adjudicar con arreglo a criterios basados en un planteamiento que atienda a la mejor relación coste-eficacia, sobre la base del precio o coste, como el cálculo del coste del ciclo de vida con arreglo al artículo 148. Este último, de forma expresa a la hora de determinar la definición y cálculo del ciclo de vida de un producto, de forma específica, contempla la valoración de aquellos costes que sean imputados a externalidades medioambientales vinculadas al producto, servicio u obra durante su ciclo de vida. La única exigencia, con el fin de poder ponderar cuantitativa o porcentualmente los mismos y así poder tenerlos en cuenta a la hora de evaluar una oferta que los contenga, lo que supone previamente tener que incluirlos en los pliegos, es que su valor monetario pueda determinarse y verificarse; estos costes podrán incluir el coste de las emisiones de gases de efecto invernadero y de otras emisiones contaminantes, así como otros costes de mitigación del cambio climático. En todo caso, remite a la normativa comunitaria, siempre que ésta haga obligatorio un método común para calcular los costes del ciclo de vida, se aplicará el mismo a la evaluación de los citados costes.

29 Esto deriva, en la mayoría de los casos, de la importancia económica y social de este ámbito, y, en todo caso, es consecuente con el propio significado de todo procedimiento administrativo.

30 Esto no supone una aplicación, en el ámbito de la contratación pública, de la autonomía de la libertad que existe en el ámbito privado. Las Administraciones en este ámbito han de actuar siempre sobre modelos y marcos que garanticen el interés público.

31 Vid. arts. 121 y ss. 
Los Pliegos de Cláusulas Administrativas Particulares (PCAP) conforman el documento básico del contrato, en el que se establecen los pactos y condiciones que definen los derechos y obligaciones que asumirán las partes del mismo, y a su contenido ha de ajustarse el propio contrato, considerándose las cláusulas parte integrante de propio contrato (art. 122), por lo que, siendo vinculantes para las partes, es frecuente que impropiamente se les considere como «la ley del contrato». Tienen carácter necesario y naturaleza contractual, en sentido de resultar obligatorio su cumplimiento para las partes ${ }^{32}$. En su contenido deben incluirse, entre otras cuestiones, las consideraciones ambientales que, como criterios de solvencia, de adjudicación o como condiciones especiales de ejecución se establezcan. Por otra parte, podrán establecer penalidades para los casos de incumplimiento o de cumplimiento defectuoso de la prestación que afecten a características de la misma, en especial cuando se hayan tenido en cuenta para definir los criterios de adjudicación, así como por incumplimiento de las obligaciones ambientales exigibles en la ejecución de los contratos (previstas en el art. 211 LCSP).

En relación con el contrato de concesión de obras, la LCSP (art. 250.1.d.7. ${ }^{a}$ LCSP) prevé que, en relación con el contenido de las proposiciones de los PCAP, los licitadores podrán introducir las mejoras que consideren convenientes, y que podrán referirse a características estructurales de la obra, a su régimen de explotación, a las medidas tendentes a evitar los daños al medio ambiente y los recursos naturales, o a mejoras sustanciales, pero no a su ubicación.

En cuanto se refiere a los Pliegos de Prescripciones Técnicas (PPT), pueden ser generales, contienen instrucciones de orden técnico con arreglo a las cuales ha de ejecutarse la prestación objeto del contrato, y particulares, pliegos y documentos que contienen las prescripciones técnicas particulares prestación y definen sus calidades, sus condiciones sociales y ambientales, de conformidad con los requisitos que para cada contrato establece la Ley que hayan de regir la realización de la (art. 124). Tras una visión rápida de los pliegos, se puede observar que, tanto en la definición de las prescripciones técnicas como en las reglas para su establecimiento, se han de tener en cuenta los aspectos ambientales, configurándose esta figura como el auténtico motor de la contratación sostenible, lo que sin duda constituye una verdadera manifestación del green nudge aplicado a la contratación pública.

Las prescripciones técnicas se definen, en función de los contratos concretos ${ }^{33}$. Así, en el contrato de obras, además de las características requeridas de un material, producto o suministro, que permitan caracterizarlos de manera que respondan a la utilización a que se destine, se incluyen, entre otros, los procedimientos de aseguramiento de la calidad, el impacto social, laboral, ambiental y climático de dichos materiales, productos o actividades que se desarrollen durante la elaboración o utilización de los mismos. En el contrato de suministros o de servicios, aquella especificación en la que se definan las características exigidas de un producto o de un servicio, como, puedan ser los niveles de calidad, los niveles de comportamiento ambiental y climático, y la evaluación de la conformidad, el rendimiento, la utilización del producto, su seguridad, o sus dimensiones, entre otras ${ }^{34}$.

Por su parte, las reglas para establecerlos se determinan en el art. 126 LCSP, debiendo proporcionar a los empresarios un acceso en condiciones de igualdad al procedimiento de contratación y no tendrán por efecto la creación de obstáculos injustificados a la apertura de la contratación pública a la competencia.

Estas Prescripciones Técnicas podrán referirse al proceso o método específico de producción o prestación de las obras, suministros o servicios requeridos, o a un proceso específico de otra fase de su ciclo de vida, ex art. 148 LCSP, incluso cuando dichos factores no formen parte de la sustancia material de las obras, suministros o servicios, siempre que estén vinculados al objeto del contrato y guarden proporción con el valor y los objetivos de este. Al vincular las Prescripciones al ciclo de vida, se vinculan a uno de los procesos más destacables a favor de la sostenibilidad de las actividades.

Además, se prevé que, siempre que el objeto del contrato afecte o pueda afectar al medio ambiente, las prescripciones técnicas se definirán aplicando criterios de sostenibilidad y protección ambiental, de acuerdo

32 Pese a lo dicho, no es posible asimilarlas a las cláusulas contractuales al uso, ya que no hay ningún tipo de negociación, ni incluso en los contratos negociados o en los de diálogo competitivo, tampoco en el nuevo tipo del contrato de asociación para la innovación, al no poder confundir la negociación para la determinación del objeto del contrato, con las propias prescripciones técnicas que están presentes en el contrato en sí mismo.

33 Vid. art. 125 LCSP.

34 Llegados a este punto, también debemos estar a lo dispuesto en el Real Decreto 314/2006, de 17 de marzo, por el que se aprueba el Código Técnico de la Edificación, incluyendo todas sus posteriores modificaciones y redacciones. Entre otras cuestiones, el Código Técnico es un instrumento para la transposición de directivas comunitarias. Así la Directiva 2010/31/UE, del Parlamento Europeo y del Consejo, de 19 de mayo de 2010, relativa a la eficiencia energética en los edificios, que propone un endurecimiento de los requisitos mínimos hasta conseguir, objetivo 2020, edificios de consumo energético prácticamente nulo. 
con las definiciones y principios regulados en los arts. 3 y 4 del Real Decreto Legislativo 1/2016, de 16 de diciembre, por el que se aprueba el Texto Refundido de la Ley de Prevención y Control Integrados de la Contaminación ${ }^{35}$.

Desde una perspectiva ambiental, las Prescripciones Técnicas se podrán formular, sin descartar otras fórmulas, en términos de rendimiento o de exigencias funcionales, incluidas las características medioambientales, siempre que los parámetros sean lo suficientemente precisos para permitir a los licitadores determinar el objeto del contrato y al órgano de contratación adjudicar el mismo (en cuyo caso, los órganos de contratación no podrán rechazar una oferta de obras, de suministros o de servicios que se ajusten a una norma nacional que transponga una norma europea, a un documento de idoneidad técnica europeo, a una especificación técnica común, a una norma internacional o a un sistema de referencias técnicas elaborado por un organismo europeo de normalización, con precisiones), o en relación con normas europeas o internacionales de Organismos de normalización, con algunas precisiones.

Con el fin de salvaguardar el principio de igualdad, con la excepción de los productos con origen sostenible, se establece que, salvo justificación por el objeto del contrato, las prescripciones técnicas no harán referencia a una fabricación o una procedencia determinada, o a un procedimiento concreto que caracterice a los productos o servicios ofrecidos por un empresario determinado, o a marcas, patentes o tipos, o a un origen o a una producción determinados, con la finalidad de favorecer o descartar ciertas empresas o ciertos productos; aunque tal referencia puede autorizarse, con carácter excepcional ${ }^{36}$.

En todo caso, la propia LCSP, art. 127, permite el uso de productos o la prestación de servicios con etiquetas (definidas como cualquier documento, certificado o acreditación que confirme que las obras, productos, servicios, procesos o procedimientos de que se trate cumplen determinados requisitos), al establecer que, cuando los órganos de contratación tengan la intención de adquirir obras, suministros o servicios con características específicas de tipo medioambiental, podrán exigir, en las prescripciones técnicas, en los criterios de adjudicación o en las condiciones de ejecución del contrato, una etiqueta específica (siempre que cumplan los requisitos establecidos) como medio de prueba de que las obras, los servicios o los suministros cumplen las características exigidas, etiquetas de tipo medioambiental, como aquellas relacionadas con la agricultura o la ganadería ecológicas, y se indicarán los requisitos de las mismas exigibles.

Como complemento de lo anterior, y con el fin de facilitar la licitación, se prevé que el órgano de contratación pueda señalar en el pliego el organismo u organismos de los que los candidatos o licitadores puedan obtener la información pertinente sobre las obligaciones relativas a la protección del medio ambiente, entre otras cuestiones ${ }^{37}$.

\section{SELECCIÓN DEL CONTRATISTA: UNA PERSPECTIVA AMBIENTAL}

El sesgo ambiental también está presente en la selección del contratista y en el procedimiento de adjudicación del contrato. Ambas figuras son parte esencial de la contratación pública (distinguiéndose en tal punto de la privada). Sin duda alguna, se trata de ámbitos en los que es primordial que las Administraciones se sometan a ciertas reglas, debido al hecho de que las solicitudes de los sujetos se han de tener en

35 Llama poderosamente la atención que pese a haberse publicado este texto en el BOE del 31 de diciembre de 2016 , sin embargo, la LCSP, del año 2017, noviembre nada menos, hace referencia al texto legal del año 2002. Con el fin de dejar a un lado el afán crítico acerca de la poca diligencia de legislador en este caso, sólo podemos entender este craso error en el espíritu del propio legislador, que, desde los primeros borradores de la LCSP, anteriores al texto refundido de 2016, quiso incluir, de forma expresa, los aspectos previstos en la normativa sobre control integrado de la contaminación en la legislación sobre contratos del sector público.

36 Esta redacción que se corresponde con el art. 126.6 LCSP, introduce un elemento de polémica, ya que de esta prohibición pudiera deducirse que, con carácter general, no se podrá exigir una procedencia determinada del producto, lo que desecharía la posibilidad de exigir el suministro o utilización de productos fruto de procesos de reciclado o ambientalmente sostenibles, es decir productos «ecológicos». No obstante, se hace necesario confrontar este enunciado con el del propio art. 126.2 LCSP, que por su parte determina que las prescripciones técnicas podrán referirse al proceso o método específico de producción o prestación de las obras, los suministros o los servicios requeridos, o a un proceso específico de otra fase de su ciclo de vida, según la definición establecida en el artículo 148, incluso cuando dichos factores no formen parte de la sustancia material de las obras, suministros o servicios, siempre que estén vinculados al objeto del contrato y guarden proporción con el valor y los objetivos de este. Luego, la interpretación acertada es que sí se podrá exigir un origen sostenible del producto, por la aplicación del propio art. 148 LCSP y la propia trascendencia del concepto de economía circular, pero no será posible ir más allá.

37 Vid. art. 129 LCSP. 
cuenta sin discriminación ${ }^{38}$. Luego razones de eficacia y eficiencia económica en el uso de fondos públicos, se traducen en la necesidad de que la Administración Pública o el ente contratante definan previamente las necesidades públicas a satisfacer con el contrato, la salvaguarda de la libre competencia y la selección de la oferta económicamente más ventajosa.

Principios que se reafirman con intensidad al comienzo del régimen de la adjudicación de los contratos, al señalar que los órganos de contratación darán a los licitadores y candidatos un tratamiento igualitario y no discriminatorio y ajustarán su actuación a los principios de transparencia y proporcionalidad ${ }^{39}$. Además, en ningún caso podrá limitarse la participación por la forma jurídica o el ánimo de lucro en la contratación, salvo en los contratos reservados para determinadas entidades, encomendando a los órganos de contratación velar en todo el procedimiento de adjudicación por la salvaguarda de la libre competencia. La contratación no puede amparar la elusión de los requisitos de publicidad o los relativos al procedimiento de adjudicación que corresponda, ni restringir artificialmente la competencia, favoreciendo o perjudicando indebidamente a determinados empresarios ${ }^{40}$.

Precisamente la regulación de la selección del adjudicatario del contrato público es donde las cuestiones ambientales se convierten en trascendentales en la LCSP. La legislación contractual anterior a 2007, contemplaba la adjudicación de los contratos generalmente mediante subasta (precio más bajo) o concurso (mediante varios criterios objetivos, en casos tasados). EI TRLCSP, recoge las mismas formas de adjudicación, si bien, el sistema gira hacia una adjudicación basada en la oferta económicamente más ventajosa, ya sea manteniendo el precio como criterio único, o estableciendo varios criterios objetivos de adjudicación (entre ellos contempla los relativos a la calidad y a las características ambientales de la prestación del contrato). Finalmente, la LCSP establece que se realizará utilizando una pluralidad de criterios de adjudicación en base a la mejor relación calidad-precio, ex art. 131.

Era ineludible que la LCSP estableciera una adjudicación de contratos como la del art. 131. Se realizará utilizando una pluralidad de criterios de adjudicación en base a la mejor relación calidad-precio, siguiendo las propuestas de la Unión Europea ${ }^{41}$, que será la regla general, pues este precepto prácticamente proscribe utilizar un solo criterio. Cierto que la Ley permite tener como base el precio o coste, pero ligado al ciclo de vida de un producto obra o servicio; por tanto, teniendo en cuenta también cuestiones medioambientales.

Aplicando el art. 145 LCSP, la mejor relación calidad-precio se ha de evaluar con arreglo a criterios económicos y cualitativos, y éstos últimos podrán incluir aspectos medioambientales o sociales, vinculados al objeto del contrato, que podrán ser, entre otros, la calidad, incluido el valor técnico, y las características medioambientales e innovadoras; características ambientales que pueden referirse, entre otras, a la reducción del nivel de emisión de gases de efecto invernadero, al empleo de medidas de ahorro y eficiencia energética y a la utilización de energía procedentes de fuentes renovables durante la ejecución del contrato, y al mantenimiento o mejora de los recursos naturales que puedan verse afectados por la ejecución del contrato. Estos criterios cualitativos deben acompañarse de un criterio relacionado con los costes, que, según el órgano de contratación, podrá ser el precio o un planteamiento basado en la rentabilidad, como el coste del ciclo de vida ${ }^{42}$.

${ }^{38}$ Conforme a los principios del art. 1 LCSP, la contratación pública debe garantizar que la misma se ajusta a los principios de libertad de acceso a las licitaciones, publicidad y transparencia de los procedimientos, y no discriminación e igualdad de trato entre los licitadores.

39 Ex art. 132 LCSP.

40 Desde el pronunciamiento del Dictamen del Consejo de Estado núm. 1270/1993, de 1 de diciembre, se estableció que el procedimiento de selección de contratistas está orientado a garantizar un trato igual a todos los licitadores y servir al interés público.

41 Vid. art. 145 LCSP. Aunque la LCSP no la recoge, la Comunicación de la Comisión "Conseguir que la contratación pública funcione en Europa y para Europa" [COM (2017) 572 final, Estrasburgo, 3-10-2017], considera que, para las autoridades públicas, la contratación es una potente herramienta para gastar el dinero público de una manera eficiente, sostenible y estratégica, especialmente en tiempos en los que los presupuestos nacionales están muy ajustados, ya que la misma asciende a 2 billones de euros cada año, lo que supone el $14 \%$ del PIB de la UE, y por ello la considera un instrumento estratégico en el conjunto de medidas económicas, reafirmando la trascendencia de la relación calidad precio cuando se gasta el dinero público, pues el precio más bajo no siempre garantiza el mejor valor; además, estima que los Estados Miembros, enfrentados a restricciones presupuestarias y a desafíos globales (como el cambio climático), deben gastar el dinero público de una manera más eficiente, sostenible y estratégica, debiendo utilizar la contratación pública como una herramienta para abordar los problemas actuales.

42 Conforme el art. 148 LCSP se entenderán comprendidos dentro del "ciclo de vida» de un producto, obra o servicio todas las fases consecutivas o interrelacionadas que se sucedan durante su existencia y, en todo caso: la investigación y el desarrollo que deba llevarse a cabo, la fabricación o producción, la comercialización y las condiciones en que esta tenga lugar, el transporte, la utilización y el mantenimiento, la adquisición de las materias primas necesarias y la generación de recursos; todo ello hasta que se produzca la eliminación, el desmantelamiento o el final de la utilización. 
La importancia de los criterios anteriores, la enfatiza aún más la LCSP al exigir a los órganos de contratación que velen por que se establezcan criterios de adjudicación que permitan obtener obras, suministros y servicios de gran calidad que respondan lo mejor posible a sus necesidades; $y$, en especial, en los procedimientos de contratos de servicios que tengan por objeto prestaciones de carácter intelectual, como los servicios de ingeniería y arquitectura (previéndose, además, que, en los contratos de servicios del Anexo IV, así como en los contratos que tengan por objeto prestaciones de carácter intelectual, los criterios relacionados con la calidad deberán representar, al menos, el $51 \%$ de la puntuación asignable en la valoración de las ofertas).

Los criterios que han de servir de base para la adjudicación del contrato se establecerán en los PCAP o en el documento descriptivo, y deberá figurar en el anuncio que sirva de convocatoria de la licitación; debiendo cumplir varios requisitos: que en todo caso estarán vinculados al objeto del contrato ${ }^{43}$; deberán formularse de manera objetiva, con pleno respeto a los principios de igualdad, no discriminación, transparencia y proporcionalidad, y no conferirán al órgano de contratación una libertad de decisión ilimitada, y deberán garantizar la posibilidad de que las ofertas sean evaluadas en condiciones de competencia efectiva e irán acompañados de especificaciones que permitan comprobar de manera efectiva la información facilitada por los licitadores con el fin de evaluar la medida en que las ofertas cumplen los criterios de adjudicación (aclarando que, en caso de duda, deberá comprobarse de manera efectiva la exactitud de la información y las pruebas facilitadas por los licitadores).

Pero no se detiene ahí la LCSP. El texto legal permite que se establezcan mejoras como criterio de adjudicación ${ }^{44}$, que propuestas por el adjudicatario pasarán a formar parte del contrato y no podrán ser objeto de modificación.

Hay que recordar que, el propio art. 145.1 LCSP permite, justificándolo en el expediente, que los contratos se puedan adjudicar con arreglo a criterios basados en un planteamiento que atienda a la mejor relación coste-eficacia, sobre la base del precio o coste, como pueda ser el cálculo del coste del ciclo de vida (con arreglo al art. 148). Pero no basta con establecer unos criterios de adjudicación de los contratos, también es preciso determinar su aplicación (art. 146 LCSP). Como ya hemos señalado, cuando se utilice un solo criterio de adjudicación, este deberá estar relacionado con los costes, pudiendo ser el precio o un criterio basado en la rentabilidad, como el coste del ciclo de vida.

Entre los criterios de adjudicación serán preferentes, siendo posible, aquellos que referencien características del objeto del contrato y puedan valorarse mediante cifras o porcentajes obtenidos a través de la

${ }^{43}$ La vinculación de un criterio de adjudicación al objeto del contrato se entiende que existe cuando se refiera o integre las prestaciones que deban realizarse en virtud de dicho contrato, en cualquiera de sus aspectos y en cualquier etapa de su ciclo de vida, incluidos los factores que intervienen en el proceso específico de producción, prestación o comercialización de, en su caso, las obras, los suministros o los servicios, con especial referencia a formas de producción, prestación o comercialización medioambiental y socialmente sostenibles y justas, o en el proceso específico de otra etapa de su ciclo de vida, incluso cuando dichos factores no formen parte de su sustancia material. Vid. Resolución núm. 136/2018 del Tribunal Administrativo de Recursos Contractuales de la Junta de Andalucía, de 10 de mayo de 2018.

Junto a la vinculación de los criterios al objeto del contrato, una jurisprudencia reiterada exige que los mismos sean adecuados y pertinentes, precisamente en atención a las características concretas de cada contrato, y que no tengan efectos discriminatorios respectos a unos empresarios frente a otros.

El cálculo de coste del ciclo de vida incluirá, según los casos, la totalidad o una parte de los costes en que se hubiere incurrido a lo largo del ciclo de vida de un producto, un servicio o una obra; en concreto, los costes sufragados por el órgano de contratación o por otros usuarios (tales como los costes relativos a la adquisición, los costes de utilización, como el consumo de energía y otros recursos, los costes de mantenimiento, y los costes de final de vida, como los costes de recogida y reciclado), los costes imputados a externalidades medioambientales vinculadas al producto, servicio u obra durante su ciclo de vida, a condición de que su valor monetario pueda determinarse y verificarse Instrucción 27/2018, de 18 de mayo, del Secretario de Estado de Defensa, por la que se establecen directrices en materia de contratación en el ámbito del Ministerio de Defensa publicada en BOD núm. 102 de 25 de mayo de 2018 (siendo posible incluir el coste de las emisiones de gases de efecto invernadero y de otras emisiones contaminantes, así como otros costes de mitigación del cambio climático); método que deberá estar basado en criterios verificables objetivamente y no discriminatorios, ser accesible para todas las partes interesadas, y que la información necesaria debe poder ser facilitada con un esfuerzo razonable por parte de las empresas.

En el supuesto de que se evalúen los costes mediante el cálculo del coste del ciclo de vida, los órganos de contratación indicarán en los pliegos los datos que deben facilitar los licitadores, así como el método que aquellos utilizarán para determinar los costes de ciclo de vida sobre la base de dichos datos. Vid. SOLA TEYSSIERE, J. (2017): "El coste del ciclo de vida como criterio de adjudicación del contrato", en Contratación administrativa práctica: revista de la contratación administrativa y de los contratistas, ISSN 1579-3036, núm. 151, págs. 6-13.

44 Vid. art. 143.1 en relación con el art. 145.7. Por mejoras se entiende aquellas prestaciones adicionales a las que figuraban definidas en el proyecto y en el Pliego de Prescripciones Técnicas, sin que puedan alterar la naturaleza de dichas prestaciones ni del objeto del contrato; y deben cumplir ciertos requisitos, como que estén suficientemente especificadas, fijando ponderadamente, con concreción los requisitos, límites, modalidades y características de las mismas, y su necesaria vinculación con el objeto del contrato, y se prevé un límite estricto, pues no podrá asignársele una valoración superior al 2,5\%. 
mera aplicación de las fórmulas establecidas justificadamente en los pliegos (precisándose los órganos que han de aplicarlos). En todo caso, la evaluación de las ofertas mediante la mera aplicación de fórmulas se realizará tras efectuar previamente la de aquellos otros criterios en que no concurra esta circunstancia, dejando constancia documental y haciéndola pública en el acto de apertura del sobre que contenga los elementos de la oferta que se valoraran mediante la aplicación de fórmulas. Será obligatorio precisar en el PCAP o en el documento descriptivo, la ponderación relativa atribuida a cada uno de los criterios de valoración ${ }^{45}$, fijando una banda de valores con una amplitud máxima adecuada, excepto que se tome en consideración exclusivamente el precio. Si el procedimiento de adjudicación se articulara en varias fases, se debe indicar igualmente en cuales de ellas se irán aplicando los distintos criterios, estableciendo un umbral mínimo del $50 \%$ de la puntuación en el conjunto de los criterios cualitativos para continuar en el proceso selectivo. No obstante, cuando, por razones objetivas debidamente justificadas, no sea posible ponderar los criterios elegidos, estos se enumerarán por orden decreciente de importancia.

Por razones de cautela, y sentido común, el art. 147 LCSP prevé que los órganos de contratación puedan establecer en los PCAP criterios de adjudicación específicos para el desempate en los casos en que, tras la aplicación de los criterios de adjudicación, se produzca un empate entre dos o más ofertas (regulando con detalle la forma y los criterios para solucionarlo) ${ }^{46}$.

Asimismo, las cuestiones medioambientales también tienen relación con las bajas temerarias u ofertas anormales o desproporcionadas, que son aquellas que resultan inviables por haber sido formuladas en términos que las hacen anormalmente bajas o desproporcionadas. La LCSP (art. 149) no permite la exclusión automática de estas proposiciones, pero permite a los órganos de contratación excluirlas del procedimiento de licitación previa tramitación del procedimiento administrativo previsto, por el cual la mesa o el órgano de contratación pueden requerir al licitador la información pertinente sobre el bajo nivel de los precios, o de costes, o cualquier otro parámetro en cuya virtud se haya definido la anormalidad de la oferta. Concretamente, podrán pedirles justificación sobre aquellas condiciones de la oferta que sean susceptibles de determinar el bajo nivel del precio o costes de la misma, en particular, en lo que se refiere al ahorro que permita el procedimiento de fabricación, los servicios prestados o el método de construcción; la innovación y originalidad de las soluciones propuestas, para suministrar los productos, prestar los servicios o ejecutar las obras, o, entre otros, el respeto de obligaciones que resulten aplicables en materia medioambiental.

En relación con éstas, la Ley es tajante, al prever que, en todo caso, los órganos de contratación rechazarán las ofertas si comprueban que son anormalmente bajas porque, entre otras cuestiones, no cumplen las obligaciones aplicables en materia medioambiental, nacional o internacional ${ }^{47}$.

\section{REFERENCIA MEDIOAMBIENTAL EN LA ADJUDICACIÓN Y EJECUCIÓN DEL CONTRATO}

Con toda la información analizada, la mesa de contratación (o el órgano de contratación, en su defecto) evaluará cuanta información y documentación proporcione el licitador en plazo y elevará de forma motivada la correspondiente propuesta de aceptación o rechazo al órgano de contratación, pero, en ningún caso, se acordará la aceptación de una oferta sin que la propuesta de la mesa esté debidamente motivada. Seguidamente, el órgano de contratación podrá excluir dicha oferta de la clasificación.

La mesa de contratación o, en su defecto, el órgano de contratación, tras clasificar por orden decreciente las proposiciones presentadas, elevará la correspondiente propuesta al órgano de contratación, salvo que el propio órgano haya realizado la propuesta. Realizada la clasificación conforme a los criterios de adjudicación señalados en el pliego, podrán solicitarse informes técnicos, excepto que el precio sea el único criterio a considerar, dado que se entenderá mejor oferta la que incorpore el precio más bajo.

Aceptada la propuesta por el órgano de contratación, presentada por el licitador la documentación justificativa pertinente, se adjudicará el contrato, mediante resolución motivada, notificada a los candidatos y licitadores y publicada en el perfil de contratante, procediendo a la formalización del mismo ${ }^{48}$.

45 Vid. art. 146.3 LCSP.

46 En su momento, ya hemos resaltado la trascendencia del ciclo de vida de los productos o servicios en relación con los criterios mencionados y en la propia adjudicación de los contratos, por lo que la LCSP (art. 148) lo define y establece la forma de calcularlo. Este criterio puede ser utilizado también como criterio de desempate.

47 Así resulta de la aplicación del art. 201 LCSP sobre ejecución de los contratos.

48 Vid. arts. 150 y ss. LCSP. 
Por lo demás, los documentos en los que se formalicen los contratos del sector público, salvo que ya se encuentren recogidas en los pliegos, deberán incluir, necesariamente, la definición del objeto y tipo del contrato, teniendo en cuenta en la del objeto las consideraciones ambientales y de innovación, entre otras ${ }^{49}$.

Ninguna duda cabe sobre que las cuestiones ambientales son esenciales como criterios para adjudicar el contrato a un licitador concreto. Pero también cobran una gran importancia en la ejecución del contrato, precisamente porque su incidencia medioambiental, en este punto, puede llegar a ser considerable, y una vez más la protección medioambiental se hace visible como una cuestión transversal u horizontal, de acuerdo con lo previsto en Derecho europeo.

En efecto, el art. 201 LCSP obliga a los órganos de contratación a tomar las medidas pertinentes para garantizar que en la ejecución de los contratos los contratistas cumplen las obligaciones aplicables en materia medioambiental, entre otras, establecidas en el derecho de la Unión Europea, el derecho nacional, o por las disposiciones de derecho internacional medioambiental que vinculen al Estado ${ }^{50}$. También pueden adoptar medidas dirigidas comprobar que los candidatos y licitadores cumplen estas mismas obligaciones durante el procedimiento de licitación, resultando del incumplimiento de estas obligaciones la imposición de penalidades ${ }^{51}$.

Además, la LCSP, ex art. 202, establece que los órganos de contratación puedan establecer condiciones especiales en relación con la ejecución del contrato (se exigirán a los subcontratistas que participen en la misma), siempre que vinculadas al objeto del contrato, no sean directa o indirectamente discriminatorias, sean compatibles con el Derecho comunitario y se indiquen en el anuncio de licitación y en los pliegos. Condiciones que podrán referirse, en especial, a consideraciones económicas, relacionadas con la innovación, de tipo medioambiental o de tipo social; siendo obligatorio, en todo caso, que el PCAP incluya al menos una de estas condiciones de entre las previstas.

En particular, la Ley permite establecer, entre otras, consideraciones de tipo medioambiental que persigan la reducción de las emisiones de gases de efecto invernadero, el mantenimiento o mejora de los valores medioambientales que puedan verse afectados por la ejecución del contrato, una gestión más sostenible del agua, el fomento del uso de las energías renovables, la promoción del reciclado de productos y el uso de envases reutilizables, o el impulso de la entrega de productos a granel y la producción ecológica ${ }^{52}$.

El incumplimiento de estas condiciones puede dar lugar a la aplicación de las penalidades establecidas, e incluso, en la forma prevista, la resolución del contrato o ser considerado como infracción grave.

\section{CONCLUSIONES}

Resulta difícil no entender la nueva Ley de Contratos del Sector si no es desde la perspectiva nudge. La integración de criterios ambientales, también de otros sociales, en todas las fases de la contratación pública, dada su regulación, hace que ésta sea una herramienta eficaz para conseguir ese objetivo de nudge de forma transversal. No se va a emplear de forma sesgada, ni tampoco como mero criterio orientador, si no que termina por convertirse en un factor de decisión a la hora de adjudicar un contrato, al igual que lo ha sido para seleccionar adjudicatarios o impedir a licitadores presentar su oferta, basándose exclusivamente en criterios ambientales.

Luego no es discutible que la nueva contratación pública responda perfectamente a ese concepto: green nudge. Concepto que no sólo es entendible y justificable, sino que además es un elemento sumamente válido y positivo en cuanto los objetivos que persigue. Sin embargo ya no resulta pacífico afirmar que ese concepto es tan nuevo como se cree. Podrá serlo su sesgo ambiental, pero no su conceptualización, al menos así lo creemos entrever, analizando obras clásicas del Derecho Administrativo, que al hablar de actividad de fomento, lo hace desde la ausencia de coacción ni de prestación directa por la Administración, que son elementos esenciales, junto con la satisfacción de necesidades de carácter público, mediante la influencia indirecta sobre la voluntad del individuo para que quiera lo que conviene para la satisfacción de

49 Ex art. 35.1.c) LCSP.

50 En particular las establecidas en el Anexo $\mathrm{V}$ de la Ley en materia de protección de la capa de ozono, control de residuos peligrosos, contaminantes orgánicos persistentes o plaguicidas y productos químicos peligrosos.

51 Tal y como dispone el art. 192 LCSP, los pliegos o el documento descriptivo podrán prever penalidades para el caso de cumplimiento defectuoso de la prestación objeto del mismo o para el supuesto de incumplimiento de los compromisos o de las condiciones especiales de ejecución del contrato que se hubiesen establecido conforme al apartado 2 del art. 76 y al apartado 1 del art. 202.

52 Vid. art. 202.2, párrafo segundo LCSP. 
dichas necesidades. No hay que denostar lo patrio por el hecho de emplear términos en lenguas extranjeras que parecen modernos y, sobre todo, desconocidos, cuando la realidad es bien distinta.

\section{BIBLIOGRAFÍA}

ALMONACID LAMELAS, V. (2013): Herramientas para el «buen gobierno» y la calidad del servicio público local en la era de las comunicaciones (o de cómo ser el ayuntamiento que el ciudadano espera), consultado el 1 de marzo de 2018, en http://www.elderecho.com/tribuna/administrativo/Buen_gobierno-calidad_del_servicio_publico_localayuntamiento_11_577930002.html.

DE LA CUÉTARA MARTÍNEZ, J. M. (1979): "Revisión de la noción española del fomento”, en Revista Internacional de Ciencias Administrativas, vol. XLV, núm. 1.

GARRIDO FALLA, F. (1962): Tratado de Derecho Administrativo, vol. II. Madrid: Instituto de Estudios Políticos.

GIMENO FELIÚ, J. M. (dir.) (2018): Estudio sistemático de la Ley de Contratos del Sector Público. Cizur Menor: Aranzadi.

JORDANA DE POZAS, L. (1949): "Ensayo de una teoría del fomento en el Derecho administrativo", en Revista de Estudios Políticos, núm. 48, págs. 41-54.

LUCERO PANTOJA, J. E. (2018): "FUNCION DE UTILIDAD. Entre el Ambiente y el Sostenimiento de la Economía", en Medio Ambiente \& Derecho. Revista Electrónica de Derecho Ambiental, núm. 32. https://huespedes.cica.es/ gimadus/32/07_funcion_de_utilidad.html.

MARTÍNEZ PALLĀRES, P. L. (2004): "El recurrente debate sobre los criterios de adjudicación de los contratos públicos. En especial la inclusión de criterios medioambientales”, en GIMENO FELIÚ, J. M. (coord.): Contratación de las Administraciones Públicas: análisis práctico de la nueva normativa sobre contratación pública. Barcelona: Atelier.

PALOMAR OLMEDA, A. y GARCÉS SANAGUSTÍN, M. (dirs.) (2018): Comentarios a la Ley de Contratos del Sector Público. Madrid: La Ley.

PERNAS GARCÍA, J. (2012): "El uso estratégico de la contratación pública como apoyo a las políticas ambientales", en LÓPEZ RAMÓN, F. (coord.): Observatorio de políticas ambientales 2012. Cizur Menor: Civitas.

PERNAS GARCÍA, J. (2011): Contratación Pública Verde. Madrid: La Ley.

RIVERO ORTEGA, R. y MERINO ESTRADA, V. (2013a): "La reforma del Régimen Local en España: necesidad, alcance, orientación y contenidos básicos", en Revista de Estudios Locales. Cunal, núm. 162.

RIVERO ORTEGA, R. y MERINO ESTRADA, V. (2013b): "La Necesidad de innovación para un buen gobierno local", en Revista de Estudios Locales. Cunal, núm. 157.

SOLA TEYSSIERE, J. (2017): "El coste del ciclo de vida como criterio de adjudicación del contrato", en Contratación administrativa práctica: revista de la contratación administrativa y de los contratistas, núm. 151.

THALER, R. y SUNSTEIN, C. (2017): Un pequeño empujón (nudge): el impulso que necesitas para tomar las mejores decisiones en salud, dinero y felicidad. Madrid: Taurus.

VARA ARRIBAS, G. (2008): "Novedades en el debate europeo sobre la contratación pública”, en Revista Española de Derecho Comunitario, núm. 26. 